\title{
The Enlightenment of Foreign Initial Carbon Emission Quota Allocation Methods to China
}

\author{
Tao-Rong GONG ${ }^{1,2, \text { a, De-Zhi LI 1, 2, *Yu-Ting LIU }}{ }^{3, \text { b }}$, Ming-Yu DONG ${ }^{1,2}$, \\ Kun $\mathrm{SHI}^{1,2}$ and Fan-Peng $\mathrm{BU}^{1,2}$ \\ ${ }^{1}$ China Electric Science Research Institute Co., Ltd., China \\ ${ }^{2}$ Beijing Key Laboratory of Demand Side Multi-Energy Carriers Optimization and Interaction \\ Technique, China \\ ${ }^{3}$ North China Electric Power University, China \\ agogntr@163.com, balice.liu@ncepu.edu.cn \\ ${ }^{\star}$ Corresponding author
}

Keywords: Carbon emission rights, Carbon emissions trading, Quota allocation.

\begin{abstract}
Environmental protection has always been the focus of our policy. Reducing carbon emissions has already been a common view among countries. China has also launched pilot projects in Shanghai, Beijing and Shenzhen. The implementation of carbon emissions trading mechanism needs to consider many factors. Among them, how to allocate the initial carbon emission quota is one of the most important issues. The choice of initial quota allocation method will directly affect the transfer of emission reduction costs among the participants and the overall cost of emission reduction. This paper summarizes the experience of carbon emission trading quota allocation in some countries and puts forward the quota allocation way of China's initial carbon emission.
\end{abstract}

\section{Introduction}

The United Nations Framework Convention on climate change and the Kyoto Protocol create a new legal right named carbon emission right. In June 18, 2013, Shenzhen officially launched the carbon trading market. In December 19, 2017, with the approval of the State Council, the national development and Reform Commission issued the national carbon emissions trading market construction plan (power generation industry). This indicates that China's carbon emissions trading system has completed the overall design and officially launched. In February 26, 2018, the National Energy Board issued the Guidance for energy work in 2018.

The allocation of carbon emission quota is of great significance to China's energy development. The more reasonable allocation of carbon emission quotas, the stronger the carbon market's role in promoting green development [1]. Carbon emission reduction is not only conducive to environmental protection, but also conducive to the optimization of industrial structure and the promotion of China's economic growth [2]. Carbon emission reduction is one of the most important aspects to promote the construction of ecological civilization in China.

In 2002, the UK adopted a voluntary carbon emissions trading mechanism. However, because the government didn't not set the highest emission target, enterprises often played the highest emission limits with the management departments, so this trading mechanism isn't successful [3]. Ronald Coase (Nobel Prize winner, economist) believes that under certain conditions, the externality or inefficiency of the economy can be corrected through the negotiation of the parties, thus maximizing the social benefits. Therefore, it is necessary to carry out the mandatory carbon emission reduction.

Nowadays, the proportion of wind power, solar power and nuclear power in China's clean energy has increased. Clean electricity will replace large quantities of thermal power, and the proportion of coal with high carbon energy will drop sharply [4]. The emission reduction effect brought about by the variety of energy consumption will play an important role. This trend reflects the feasibility of China's 2020 emission reduction targets. 
In August 2017, the United States formally submitted a letter of intent to withdraw from the Paris agreement. This not only shook the determination of global carbon emission reduction, but also increased the emission reduction burden of other countries [5]. The gap between the comprehensive emission reduction effect and the final temperature rise target of the original state contribution has increased by $8.8 \%$ to $13.5 \%$ from the 150 billion ton carbon dioxide equivalent gap. As the largest developing country in the world, the task of reducing carbon emissions is very arduous.

Although the above documents put forward the guiding ideology and the basic construction plan of carbon emissions trading, there are still some defects in the current system of carbon emission distribution in China [6]. In fact, not only in China, most countries and regions that carry out carbon emissions trading have certain defects in the quota allocation system. Former US Vice President Gore once pointed out that the effective allocation should be to allocate quotas to those who are most valuable to them. In fact, such an ideal distribution is difficult to achieve. This paper first analyzes the carbon emission quota issuing mechanism of some typical countries and regions, and then analyzes the advantages and disadvantages of different mechanisms. Then we will set up the quota mechanism of carbon emissions trading in China, so as to make the distribution mechanism more reasonable.

\section{Distribution Method of Transaction Quotas and Their Advantages and Disadvantages In Typical Countries}

\section{Allocation of Regional Trade Quotas in Some Countries}

\section{(1) European Union}

The quota distribution mechanism of the EU greenhouse gas emissions trading market has two main features: the free distribution of quotas, the total amount of quotas obtained by the market participants based on its historical emission level (grandfather law). Grandfather Law is the main way of quota allocation in the first phase (2005-2007 years) and the second stage (2008-2012 years) of the EU greenhouse gas trading market. In 2009, according to the experience of the past two stages, the European Commission revised the legal framework for regulating the trading market [7]. The revised contents included reclaiming the power of the member states to determine their own emissions and quota allocation in 2013-2020, limiting the total emissions of European Union integration, expanding the coverage of the trading market and incorporating the aviation industry, and formulating a time table from the free distribution of quotas to the auction law.

(2) America

In January 1, 2009, the Regional Greenhouse Gas Initiative (RGGI) was launched in the United States, which aimed to reduce the emission of greenhouse gases in the United States. The allocation of carbon emissions quotas is one of the core contents of the project. According to the contents, the allocation of quotas between States is based on historical emissions, energy consumption, population, and new sources of emissions. Direct allocation of facilities and allocation of power plants are usually carried out by the states themselves. The quota allocation plan of power plants is similar to the NOX budget transaction plan. Among them, it is worth mentioning that all emission quotas are issued through regional auctions once every three months [8].

(3) Australia

Australia government has adopted the way in which participants purchase quotas from the government through fixed prices. In the fixed price period, in addition to a small amount of free amount issued by the government, the participants need to buy excess emission limits to the government according to the total amount of their emissions during the year. Australia's carbon quota allocation has fully absorbed the lessons learned from the practice of EU carbon trading market, such as the fluctuating and fluctuating carbon prices. Australia has adopted a strategy of gradual marketization. Three years fixed market price, three years set market price floating interval, and finally transition to market determined price entirely.

(4) New Zealand

New Zealand's greenhouse gas emissions trading market adopts mixed quota allocation. Taking into account the differences in various industries, it tries to guide all kinds of resources to industries 
with high contribution rate. The mixed quota allocation method takes into account the obvious differences in the proportion of greenhouse gases and total economic output in various industries. Different industries will bear different responsibilities in the emissions trading market. The coverage of the trading market gradually expanded on the basis of industry, and began to cover only the forestry, energy, fishery, industrial and liquid fuels industries. In 2013, it was extended to the synthetic gas and waste treatment industries.

(5) Tokyo

Unlike other regions, the mandatory volume cap trading system in Tokyo contains many small emission facilities. In order to reduce the default burden and transaction costs of smaller enterprises, the government will subsidize small manufacturers to enhance their energy efficiency. In order to achieve the goal, the options available for enterprise emission facilities include reducing internal emissions, buying carbon emissions from other economic entities with strong emission reduction capacity and buying domestic carbon offset for small and medium-sized enterprises. For emission facilities that do not meet the emission reduction targets, the government will impose a penalty of 1.3 times the amount of breach of contract in the next stage.

\section{Advantages and Disadvantages of Various Methods}

(1) Grandfather Law (EU)

Advantages: This method has greatly weakened the willingness of the exhaust enterprises to resist participating in the transaction and stimulated the enthusiasm of the market participants to participate in the transaction. [9]

Disadvantages: 1 . There are problems in fairness and efficiency ;2.Encourage enterprises to increase emissions and strike enterprises' initiative in reducing emissions

(2) Quota auction (America)

Advantages: To a certain extent, this method makes up for the lack of efficiency and fairness caused by grandfather law, which can better play the role of carbon trading market to effectively configure the emission reduction resources. [10]

Disadvantages: 1. Lack of experience; 2. Quota auctions covering all industries may lead to unfair situations between industries and enterprises.

(3) Fixed price purchase (Australia)

Advantages: Form a stable price signal and reasonable anticipation of all participants. It can effectively promote the flow of funds and technology to the field of emission reduction.

Disadvantages: The policy environment is not stable enough, changing greatly, which is not conducive to long-term development.

(4) Mixed quota allocation(New Zealand)

Advantages: The mixed quota allocation method is relatively fair and reasonable, which improves the efficiency of emission reduction.

Disadvantages: Free quotas, offset quotas and purchase quotas may exist simultaneously in the same industry.

(5) Compulsory total quota trading system(Tokyo)

Advantages: 1.Achieve the environmental goal of energy saving and emission reduction easily

2. Improve the liquidity of carbon trading market

3. Improve the efficiency of the whole regulation system

Disadvantages: Increase enterprises’ costs

(6) Historical emission law and baseline method(China)

Advantages: From the results of the pilot, this method has maintained a stable market situation, the participants gradually increased, the volume of market transactions increased and the transaction price was relatively stable.

Disadvantages: 1 . the allocation method of different supply chain locations in the same industry is unfair; 2 . the proportion of paid distribution is too little 


\section{The Method of Quota Allocation in China}

\section{The Characteristics of Trading in China}

(1) Different allocation methods for different participants

1) Power industry

The power industry is a monopolized industry controlled by the state. For the electric power industry, the free distribution is the main way to encourage the power industry to participate in carbon emission reduction. The free distribution method can relieve the pressure of carbon emission reduction system practice. This not only does not increase the cost of power companies, but it will add an asset that can be sold on the market for those who have completed a partial reduction in the market, thus promoting the development of the carbon trading market. In order to economize on this aspect, manufacturers who need to purchase carbon emissions will improve their equipment performance or optimize the production process to reduce carbon emissions in the next period.

2) Production industry

High energy consuming industries such as non-metallic mineral products, metal smelting and calendering processing, paper and paper products industry is highly affected by electricity price. If the electricity price rises, the cost of the industry will also increase. Therefore, the free distribution method in the power industry also reduces the cost pressure of the industrial sector. The mixed quota allocation method should be adopted for the allocation of initial carbon emissions trading quotas in production industries. In order to increase equity, it should be improved in New Zealand's original model.

(2) Large regional differences

China's territory is vast, and there are differences in GDP among different regions. Different regions have different resources and minerals, and the gross industrial output is quite different. When setting up the initial carbon emissions trading quota, the local industry should proceed from the actual situation of the local industry and customize it according to the previous emission values and the local industry development speed.

\section{Conception of Quota Allocation Method for Initial Carbon Emission Trading in China}

\section{The Distribution Method of Historical Emissions as a Distribution Index}

As long as production activities are carried out, enterprises will produce corresponding carbon emissions. The carbon emissions of enterprises are closely related to the scale and output value of enterprises. Usually, emissions do not change dramatically. Based on the relationship between carbon emissions and enterprise production, China takes it as an important basis for the allocation of transaction quotas.

$$
A^{*}=\frac{E^{*}}{E} * A
$$

Among them, A is the total carbon emission weight of the country in that year. $\mathrm{E}^{*}$ is the carbon emissions from industry in the benchmark year. $\mathrm{E}$ is the total amount of carbon emissions of the country in the benchmark year. The selection of base year is particularly important. The base year can be selected for several years or just one year. Choosing a different base year will bring different impacts to enterprises. If you choose only one year, the uncertainty is too high. If you choose a few years, such as 3-5 years of data, it will be relatively objective.

But this objective is only relative to the choice of one year's data. In this paper, the parameter $\alpha$ and $\beta$ are introduced. The parameter $\alpha$ represents the growth trend of the industry's emission. The parameter $\beta$ means the growth trend of the branch's emission. Thus, the formula (1) is changed into:

$$
\begin{gathered}
A^{*}=\frac{E^{*} * \alpha}{E} * A \\
\alpha=\frac{\sum_{i=1}^{n} x_{i+1}}{\sum_{i=1}^{n} x_{i}}
\end{gathered}
$$




$$
\beta=\frac{\sum_{i=1}^{n} y_{i+1}}{\sum_{i=1}^{n} y_{i}}
$$

In the formula, $x_{i}$ is the branch's carbon emissions for the year $i . y_{i}$ is the total amout of carbon emissions of the industry for the year $i$.

\section{Example Analysis 1}

This paper selects carbon emission data of thermal power industry for 2007-2012 years to allocate carbon emissions in thermal power industry in 2015. (National Bureau only has statistics data to 2012, predicting 2015 statistics has practical value.)

Table 1 2007-2012 annual electricity generations in thermal power industry

\begin{tabular}{|l|l|l|l|l|l|l|}
\hline Year & 2007 & 2008 & 2009 & 2010 & 2011 & 2012 \\
\hline $\begin{array}{l}\text { Power } \\
\text { output }\end{array}$ & 3281.553 & 3466.882 & 3714.65 & 4207.16 & 4713.02 & 4937.77 \\
\hline
\end{tabular}

Unit: billion kilowatt hour

According to the formula: carbon emission = emission factor * power generation, we can get the $\alpha=1.07, \beta=1.06$ in which the emission value of the base year selects 2007-2012.

Table 2 2007-2012 annual carbon emissions in thermal power industry

\begin{tabular}{|l|l|l|l|l|l|l|}
\hline Year & 2007 & 2008 & 2009 & 2010 & 2011 & 2012 \\
\hline $\begin{array}{l}\text { Carbon } \\
\text { emissions }\end{array}$ & 2.51 & 2.65 & 2.84 & 3.21 & 3.61 & 3.78 \\
\hline
\end{tabular}

Unit: billion ton

Through the growth rate of GDP in China, we can predict that the carbon emissions in 2015 would be about 9.8 billion tons. Taking the above data into the formula, the amount of emissions in 2015 is about 4.82 billion tons. Then use SPSS to fit the data. We compare the degree of data fitting before and after the introduction of parameter $\alpha$ and $\beta$. Before the introduction of parameter $\alpha$ and $\beta$, $\mathrm{R}^{2}=0.974$. After the introduction of parameter $\alpha$ and $\beta, \mathrm{R}^{2}=0.988$. It can be concluded that the introduction of parameters is more consistent with the logical trend.

Table 3 Before the introduction of parameter $\alpha$ and $\beta$

\begin{tabular}{|c|c|c|c|c|c|c|c|}
\hline \multirow[b]{2}{*}{ Equation } & \multicolumn{5}{|c|}{ Model summary } & \multicolumn{2}{|c|}{ Parameter evaluation } \\
\hline & $\mathrm{R}^{2}$ & $\mathrm{~F}$ & df1 & df2 & $\begin{array}{c}\text { significan } \\
\text { ce }\end{array}$ & Constant & b1 \\
\hline Linear & .974 & 190.648 & 1 & 5 & .000 & -657.428 & .329 \\
\hline
\end{tabular}

Table 4 After the introduction of parameter $\alpha$ and $\beta$

\begin{tabular}{|c|c|c|c|c|c|c|c|}
\hline \multirow[b]{2}{*}{ Equation } & \multicolumn{5}{|c|}{ Model summary } & \multicolumn{2}{|c|}{ Parameter evaluation } \\
\hline & $\mathrm{R}^{2}$ & $\mathrm{~F}$ & df1 & df2 & $\begin{array}{c}\text { significa } \\
\text { nce }\end{array}$ & Constant & b1 \\
\hline Logistic & .990 & 499.157 & 1 & 5 & .000 & $3.575 E+73$ & .919 \\
\hline
\end{tabular}

\footnotetext{
${ }^{1}$ In the example, the industry data came from National Bureau of Statistics of China
} 


\section{Conclusion}

According to the empirical test results, it is feasible to allocate the future carbon emission quota in the industry through the historical discharge of the electricity industry. The advantages of this method including: 1. Encourage the participation of the participants in the emission reduction initiative; 2.The participants can reduce their carbon emissions by optimizing the equipment to enhance energy efficiency. The remaining carbon emission quotas can be sold to other enterprises and then the sellers gain profits.

In the long run, China should not always distribute quotas free of charge. After a few years of free quota model, many participants have a deeper understanding of energy conservation and emission reduction, then change the model to auction or subscribe for carbon emissions quotas. Auction model helps to stimulate the vitality of the market. The initial quota for auctions can be calculated by combining historical emissions with China's emission reduction targets.

\section{Acknowledgement}

This research was financially project supported by national Power Grid Corp headquarters: Research on operation simulation and effectiveness evaluation of electricity market (YDB17201600102)

\section{References}

[1] Li Yan. Fujian carbon emissions trading pilot status, problems and recommendations [J]. Macroeconomic Management, 2018 (02): 66-71.

[2] Xiao Wenhai, Wei Wei, Dong Anping. Preliminary study on initial quota allocation and price setting of carbon emissions trading in Jiangxi [J]. Poyang Lake journal, 2015 (01): 90-95.

[3] Tang Li, 2010. Speech at the "Global Forum on low carbon finance" sponsored by the people's Bank of China and the Tianjin municipal government, Tianjin, September 10th

[4] Zhao Qiaozhi, Yan Qing you, Zhao Hairui. Spatial characteristics and influencing factors of China's provincial carbon emissions [J]. Journal of Beijing Institute of Technology (SOCIAL SCIENCES), 2018,20 (01): 9-16.

[5] Chai Chi min, Fu Sha, Xu Huaqing, Ma Aimin. The Trump administration announced the withdrawal of the Paris agreement analysis and countermeasures. [J]. China development observation, 2017 (12): 5-10+55.

[6] Li Wei. Summary of China's research on carbon emissions trading [J]. Reference to economic research, 2017 (42): 36-48.

[7] European Parliament of the Council. Directive 2009 /29 /EC (Amending Directive 2003 /87 /EC so As to Improve and Extend the Greenhouse Gas Emission Allowance Trading Scheme of the Community) [R]. 2009:63-87.

[8] Jiang Xiaochuan. The initial allocation system of carbon emissions in China [D], 2012, Jiangxi University of Finance and Economics. 